\title{
ACTIVIDADES TRADICIONAIS E EMPREGO FEMININO NO MONTEMURO: NOTAS DE REFLEXÃO SOBRE O DESENVOLVIMENTO LOCAL
}

\author{
Carlos Peixeira Marques* \\ José F. G. Portela **
}

\section{INTRODUÇÃO}

Este texto é uma reflexão sobre o desenvolvimento local em meio rural, baseada no nosso contacto com micro-empresas de produção e comercialização de artesanato, situadas na Serra de Montemuro (Marques, Portela e Cristóvão, 1993).

Trata-se duma "área rural profunda", segundo a classificação da Comissão de Coordenação da Região Centro (CCRC), onde $90 \%$ da população vive em lugares com menos de 500 habitantes e $50 \%$ em lugares com menos de 200 habitantes ${ }^{1}$. Isto apesar dos movimentos migratórios, com saldo negativo de $12 \%$ entre 1981 e $1991^{2}$, terem afectado as localidades mais pequenas. Naquela área do interior do país, o envelhecimento populacional manifesta-se duplamente no aumento dos idosos e diminuição dos jovens, mas é precisamente na base da pirâmide que mais se faz sentir: entre 1981 e 1991 houve um decréscimo de $30 \%$ na população até aos 14 anos e de $20 \%$ entre os 15 e os 24 anos $^{3}$.

$\mathrm{O}$ difícil acesso das gentes do Montemuro às oportunidades de educação e de emprego e o consequente despovoamento têm motivado diversas intervenções de agências de desenvolvimento, nacionais e estrangeiras. Dentre elas, destacaríamos as do Institut of Cultural Affairs (ICA) e as da Comissão da Condição Feminina, posteriormente designada Comissão para a Igualdade e para os Direitos das Mulheres (CIDM). Foi precisamente num projecto coordenado pela CIDM que realizámos a nossa observação, entre fíns de 1992 e meados de 1993.

\footnotetext{
* Universidade de Trás-os-Montes e Alto Douro; Instituto Universitário de Desenvolvimento e Promoção Social — Pólo de Viseu da Universidade Católica Portuguesa.

** Universidade de Trás-os-Montes e Alto Douro. Presidente da ANIMAR - Associação Portuguesa para o Desenvolvimento Local em Meio-Rural.
} 
Expomos neste artigo duas constatações resultantes desse trabalho de campo, a saber:

$1 .^{\mathrm{a}}$ em comunidades rurais onde, tradicionalmente, a ligação à sociedade global era sobretudo assegurada por homens, as mulheres podem constituir-se como eixos de mudança e iniciativa;

$2 .^{a}$ as micro-empresas estabelecidas em meio rural, designadamente as que oferecem produtos tradicionais, assentes numa lógica económica de pluriactividade e pluri-rendimento, podem ser um forte contributo para o desenvolvimento local.

A primeira constatação está também ilustrada, por exemplo, num artigo sobre uma intervenção junto de mulheres da mesma área geográfica (Gomes, 1986): por indução de agentes externos, as mulheres envolvidas construíram novas imagens das suas relações com a família e a comunidade, o que, inevitavelmente, afectou o seu status e os seus papéis ${ }^{4}$. Consequentemente, a comunidade não poderia deixar de ser afectada. Esta capacidade de mobilização, contra o que é por muitos tido como o destino das aldeias do interior, foi por nós bastas vezes notada quando as mulheres nos afirmavam que, através da criação de emprego feminino com "salários dignos", poderiam ficar na sua terra, cuidar dos seus velhos, ter mais perto os seus maridos. E não precisariam de enfrentar a insegurança da grande cidade ou da língua desconhecida.

O sonho de satisfazer novas aspirações sem deixar a terra manifesta-se, graças à ajuda das agências de desenvolvimento referidas e a programas de apoio do Estado e da União Europeia, na criação das micro-empresas, objecto da seguinte secção deste artigo.

Para se poder chegar à segunda constatação, tratada no final do texto, é necessário passar pelas duas secções intermédias, consagradas a factores que facilmente podem transformar o sonho em pesadelos:

- em primeiro lugar, a hostilidade social, frequentemente com dupla origem: urbana, porque se trata de micro-empresas, cooperativas, sem viabilidade nem visibilidade; e rural, porque se trata de "coisas de mulheres";

- em segundo lugar, as fraquezas e forças relativas à competitividade destas empresas.

\section{COOPERATIVAS DE ARTESÃS: O SONHO}

As cooperativas ${ }^{5}$ surgem ou por iniciativa de líderes locais, com facilidade de relacionamento no meio exterior à comunidade e que, normalmente, não partici- 
pam nas actividades produtivas, ou fundadas por mulheres que foram sujeitas a formação pessoal e profissional por parte de agentes de desenvolvimento (nomeadamente, a CIDM e o ICA) e se sentiram encaminhadas para esta solução ${ }^{6}$.

Ainda antes da constituição de cooperativas, as mulheres são atraídas para a formação profissional, segundo a lógica do pluri-rendimento. A bolsa de formação é uma espécie de prestação social do Estado-Providência, no geral bem aproveitada, por exemplo, pelas jovens solteiras que, após o casamento, partem para a Suíça ou para o litoral em busca dum emprego assalariado.

As mulheres que se integram nas cooperativas têm o sonho de poderem vir a realizar um trabalho fora da actividade agrícola, como complemento ou fonte exclusiva de rendimento. Devido a problemas vários, com destaque para as dificuldades de comercialização, tal sonho é, nalguns casos, efémero, e a actividade artesanal tende a subsistir como subterrânea. Felizmente, também há casos de relativo sucesso comercial. No entanto, o que mais nos interessa registar, por agora, é a maneira como se manifesta este sonho, nalguns casos definido por expectativas muito concretas. Algumas mulheres por nós entrevistadas referiram explicitamente que o homem não precisa de procurar actividade remunerada fora da aldeia, se a remuneração que elas auferirem na cooperativa satisfizer as aspirações familiares de consumo.

Se pensarmos na hipótese, frequentemente apresentada, que liga a feminização da agricultura à substituição de mão-de-obra masculina, desviada para outros sectores de actividade (Wall, 1986: 662-663), verificamos aqui potencialidades duma inversão do fenómeno. A pluriactividade feminina suportada pelo artesanato assume assim grande importância para reter os casais no meio local, dada a escassez de oportunidades de assalariação (local) dos homens. Ora, esta retenção não só pode contribuir para um equilíbrio demográfico, como é uma condição necessária a um modelo de desenvolvimento rural que aposte nas "explorações rurais" (Cavaco, 1991: 26 ss.).

Resumindo, podemos dizer que o sonho nasce do contacto com novas realidades, normalmente estranhas ao meio local, e é abraçado pelas líderes locais, ajudadas por agentes externos. Do nosso ponto de vista, este sonho pode constituir um dos pilares do desenvolvimento local. Mostraremos em seguida como não só certos actores sociais urbanos, como a própria comunidade local confrontam as sonhadoras com realidades que tornam ténues as fronteiras dos pesadelos.

\section{HOSTILIDADE SOCIAL ENVOLVENTE: OS PESADELOS}

As políticas oficiais de "igualdade de oportunidades" têm grandes dificuldades de implantação no terreno, encontrando consideráveis barreiras, ligadas a atitudes 
profundamente enraizadas, que terão como função garantir a ordem social e as ideologias dominantes (Marques, Portela e Cristóvão, 1993: 8).

É um facto que, em geral, os grupos mais desfavorecidos, destinatários de tais políticas, não têm capacidade para lidar com as burocracias criadas para as executar. Várias razões podem ser apontadas para explicar este facto, dentre as quais destacaríamos a miopia sociológica e o etnocentrismo dos funcionários, manifestando-se, neste caso, na desvalorização de empresas que, à imagem das aldeias onde se constituem, não são grandes nem modernas.

A hostilidade social envolvente (Portela, 1994: 49 ss.) começa, portanto, por afectar as mulheres do Montemuro da mesma maneira que afecta as populações rurais em geral, nomeadamente nas suas relações com organismos do Estado. Surgem nestas relações os primeiros pesadelos, bem expressos por uma artesã: "é tudo papéis; aqui não sabemos nada de papéis". Há, no entanto, a acrescentar nas cooperativas de artesãs duas novas dimensões de desigualdade de oportunidades reproduzidas pela burocracia que as deveria atenuar. Em primeiro lugar, sendo cooperativas, são facilmente associadas a não-lucrativas. Em segundo lugar, sendo de mulheres, merecem uma desvalorização social extensível às organizações preocupadas com a desigualdade sexual ${ }^{7}$ e mesmo aos programas comunitários criados para atenuar esta desigualdade (Marques, Portela e Cristóvão, 1993: 8 ss.).

Para além dos problemas de relacionamento com a sociedade global, há que registar uma hostilidade da própria comunidade local para com as mulheres envolvidas nas cooperativas. Fazendo-se sentir com maior impacto nas fases iniciais da vida das cooperativas (mesmo antes do nascimento), tal hostilidade é por nós interpretada como uma reacção natural às mudanças no status e papéis das mulheres e consequente impacto na estrutura social local.

A categorização social destes empreendimentos como "coisas de mulheres", não devendo, por isso, ser levados a sério, é uma manifestação da ameaça sentida pela ordem dominante. $\mathrm{O}$ estatuto jurídico das cooperativas facilita ainda a equiparação das cooperantes à categoria de "comunistas", a qual deve ser entendida como equivalente a subversivas. Num dos casos, era mesmo utilizado um termo atentatório da honra das artesãs, para designar o espaço físico construído para albergar a cooperativa. Aliás, a subversão da moral e dos valores locais é frequentemente associada a projectos de desenvolvimento pelo facto de estes provocarem mudança: "Não vais a reuniões, só vai para lá quem não sabe fazer o comer. Elas falavam que nos iam ensinar a fazer o aborto, que nos vinham ensinar a mandar nos maridos" (Koning, 1986: 839).

Mesmo quando as realidades proporcionadas pelo sonho induzem a mudança de atitudes e as empresas de mulheres são melhor aceites pela comunidade, a desigualdade sexual continua a criar dificuldades ao seu sucesso económico. Vejamos um exemplo. As exposições e feiras de artesanato são não só importantes even- 
tos promocionais como boas ocasiões de venda. Ora, algumas mulheres têm dificuldades em participar nesses eventos por causa da pressão social que estigmatiza os maridos que as "deixam dormir fora de casa".

\section{FRAQUEZAS E FORÇAS DAS MICRO-EMPRESAS DE ARTESÃS}

A criação e desenvolvimento das micro-empresas de artesãs referidas está estreitamente ligada às intervenções de várias agências de desenvolvimento, como já vimos, e a vários projectos de formação, a maioria dos quais integrados em Programas do IEFP/FSE. Tais acções permitem, a algumas artesãs, um certo domínio de alguns instrumentos de gestão e até mesmo uma percepção estratégica do negócio em que estão envolvidas. Isto, infelizmente, não é muito comum e nunca é comungado por todas as artesãs num mesmo grupo.

Tanto quanto a nossa análise nos permitiu concluir, esta percepção estratégica e a preocupação com aspectos como o design e o marketing devem sobretudo ser atribuídos à interacção das artesãs com os técnicos e dirigentes da Rede de Comercialização de Artesanato (RCA), um projecto de parceria que decorreu entre 1991 e 1993, ao abrigo de um Programa Operacional de Mulheres (IEFP). O desenvolvimento de produtos, consistindo no fabrico tradicional com novo design, adaptado a clientes urbanos, foi uma das realizações mais significativas da RCA, envolvendo e motivando fortemente muitas artesãs. A diferenciação dos produtos aparece já hoje, pelo menos nalguns casos, como um bom trunfo concorrencial destas micro-empresas.

Esta diferenciação de produtos é possível graças à recuperação da cultura tradicional. É inegável o contributo de técnicos externos, particularmente estilistas, mas foi indispensável o envolvimento das mulheres locais: das mais novas, com o seu sonho e a sua iniciativa; das mais velhas, com o seu saber-fazer, o domínio sobre recursos locais, que herdaram dos antepassados e que parecia condenado a morrer com elas. A singularidade do local, cristalizada nos tempos, é, assim, uma das principais riquezas destas empresas.

A manifestação da cultura local no saber-fazer é uma fonte adicional de motivação e satisfação no trabalho. A procura dos produtos é o reconhecimento do saber-fazer comungado pelas artesãs. $O$ interconhecimento pessoal, se bem que possa aguçar problemas de liderança interna, quando os houver, é outro motor de motivação porque facilita o sentimento de posse, de domínio sobre os objectos produzidos.

No entanto, para além dos estrangulamentos na distribuição, que arrefeceram muito do ânimo inicial, e dos constrangimentos ambientais, aos quais já fizemos uma breve alusão, subsistem ainda muitos problemas na gestão destas pequenas 
empresas, os quais podem ser resumidos da seguinte forma (Marques, Portela e Cristóvão, 1993: 14 ss.):

a) indefinição da missão e dos objectivos;

b) indefinição orgânica;

c) necessidades de fundo de maneio, agravadas pelas dificuldades de domínio dos instrumentos contabilísticos e de gestão financeira, não havendo controlo sobre o crescimento do activo circulante;

d) deficiências no atendimento aos clientes e mesmo na sinalização e publicidade dos locais de venda directa ${ }^{8}$.

Cremos, portanto, que haverá todo o interesse em continuar o trabalho de formação, melhorando alguns aspectos de gestão, nomeadamente o marketing e as finanças, e ajudando as artesãs a adaptarem as suas formas de racionalidade às realidades concorrenciais da comercialização dos seus produtos. No entanto, qualquer tipo de trabalho, neste sentido, não poderá perder de vista o contexto de pluriactividade, fundamental para compreender que a eficácia socioeconómica destas unidades não é mensurável segundo critérios de eficiência empresarial.

Como já foi dito, a diferenciação da oferta destas empresas assenta na tecnologia de produção, não industrial, e na genuinidade local dos produtos. Apesar da presumível singularidade dos critérios de compra ${ }^{9}$ dos nichos de mercado aos quais se destinam, a comercialização destes produtos enfrenta problemas concorrenciais com bens industriais não genuínos, os quais não podem ser ultrapassados isoladamente pelas empresas. Como fazem notar alguns autores, "os produtos rurais, porque de pequena escala, não poderão competir em termos de preço com outros de tipo marcadamente industrial e, para competirem em termos de qualidade, necessitariam de intervir no processo de formulação da decisão dos consumidores, ou seja, de aparecer nos grandes meios de comunicação social ${ }^{10}$, mas de que estão afastados pela sua pequena dimensão e fracos recursos" (Jacinto et al., 1993: 15).

Acreditamos nas potencialidades duma associação ou rede de comercialização para ultrapassar este círculo vicioso. Uma organização que seja capaz de proporcionar economias de escala em marketing, promover a realização de estudos sobre os mercados, aumentar o poder negocial face a fornecedores e clientes. É ainda necessário uma organização que, movimentando-se na Europa dos $l o b$ bies, garanta a certificação da genuinidade e afaste os padrões unificadores, regulando a entrada de novos concorrentes e diminuindo as ameaças dos substitutos industriais.

Construir uma organização deste tipo não será tarefa fácil nem rápida, faltando ainda definir quem poderá chamar a si esta iniciativa. Haverá que escolher o critério que servirá de base à estruturação (o tipo de produtos ou a região, por exem- 
plo), de modo a facilitar o contacto com as micro-empresas e com os intermediários da comercialização. $O$ que poderemos desde já adiantar é que, para garantir a eficácia desta organização, será necessário conhecer profundamente as realidades das inúmeras micro-empresas de artesanato e produtos locais existentes em Portugal. Saber ouvir as pessoas envolvidas e dar-lhes oportunidade de se manifestarem é essencial para o desafio de ultrapassar a lógica assistencialista e construir uma estrutura de comercialização sustentável. Como bem observou Villaverde Cabral (Cabral, 1983: 227), existe uma forte resistência do artesão em transformar-se em empresário, a par duma propensão à subterraneidade, a qual se verifica mesmo no seio de associações de comercialização ${ }^{11}$. Esta venda 'clandestina', à revelia das associações ou redes, é sobretudo motivada pelo poder negocial dos clientes (intermediários), pelo que a estrutura de comercialização de que temos vindo a falar terá que provar às artesãs o seu poder negocial, para que as pequenas empresas e cooperativas possam vir a financiar as acções de pesquisa, promoção, etc. Trata-se de conseguir neste campo o que já se conseguiu no design.

Guardámos para o final desta seç̧ão um ponto forte destas empresas, comum a todas as unidades económicas que, não sendo capitalistas, coabitam no sistema capitalista: não têm que se sujeitar a critérios de eficiência económica. Cumprem assim uma função social muito importante, permitindo às artesãs a gestão do seu tempo de modo a cuidarem dos filhos, do marido, dos velhos, da horta. Vantagens assinaláveis sobre a vida citadina, que permitem a retenção de algumas jovens mulheres e, por consequência, de homens, abrindo as portas à revitalização da aldeia.

\section{MICRO-EMPRESAS DE ARTESÃS, EXPLORAÇÕES RURAIS E DESEN- VOLVIMENTO LOCAL}

Há hoje uma certa aceitação, cada vez mais generalizada entre os decisores políticos, de que em "áreas rurais profundas", como a que aqui tratamos, a valorização dos recursos tradicionais locais deve constituir o suporte do desenvolvimento. Por exemplo, no texto do Plano de Desenvolvimento Regional 1994-99, "a valorização do mercado dos produtos tradicionais, a organização de formas de pluriactividade e a diversificação de fontes de rendimento familiar" são "linhas estratégicas" da redução de assimetrias inter e intra-regionais. Parece tratar-se duma condescendência à pluriactividade possível em áreas sem grandes oportunidades de emprego assalariado, onde não há emergência de centros urbanos chamados de média dimensão. Em nossa opinião, deve ser uma alternativa à industrialização difusa, feita à custa de incentivos autárquicos e mão-de-obra barata e desqualificada ${ }^{12}$, uma vantagem comparativa cada vez menor, face à concorrência de outras áreas do Globo. 
A lógica da multiplicação das fontes de rendimento tem sido ligada à "incapacidade estrutural da agricultura para remunerar o trabalho de molde a satisfazer as presentes aspirações das famílias rurais" (Cabral, 1981: 143). A questão das aspirações joga aqui um papel fundamental: uma técnica por nós entrevistada, que lidou com artesãs de várias regiões, afirmava-nos que os rendimentos pretendidos pelas artesãs do Minho eram claramente superiores aos pretendidos pelas do Montemuro ${ }^{13}$. Ora, as mudanças induzidas pelas diversas agências de desenvolvimento, que têm actuado no Montemuro, não podem deixar de se sentir também ao nível das aspirações. O próprio aumento da escolarização, particularmente da escolarização feminina, também contribuiu para o aparecimento de novas aspirações, pelo que é natural ver partir as jovens quando as bolsas de formação acabam e as incertezas da comercialização do artesanato começam.

Quer isto dizer que o sucesso destas cooperativas de artesanato é muito importante para o desenvolvimento local, para que não só as mulheres, como os seus maridos, possam realizar os seus sonhos na sua terra, onde querem ter a sua casa e a sua sepultura. Relembre-se o que foi dito acima sobre uma potencial remasculinização da agricultura e acrescente-se o objectivo de uma cooperativa, segundo as palavras de uma artesã: "empregar mais mulheres para toda a aldeia viver bem".

Os actuais problemas de comercialização e de imagem do seu artesanato são fontes de frustração, pois não foram só as formações pessoal e profissional que aumentaram as suas aspirações, foram as próprias realizações a nível de design e qualidade conseguidas no âmbito da RCA e, no fim de contas, algum "dinheirito que sempre se tem ganho".

Ultrapassar esses problemas não é fácil, mas parece um pequeno passo, quando consideramos o capital de formação já investido nestas mulheres, o qual constitui a base para que elas possam tornar-se elementos centrais na formação de explorações rurais orientadas para "consumidores que procuram bens com uma imagem de autenticidade, de natural, de tradicional" (Cavaco, 1991: 31), tal como já o foram na mudança das atitudes locais face à saúde, à sexualidade, à educação $\mathrm{e}$ mesmo face ao trabalho.

Como se nota num trabalho de caracterização de iniciativas de desenvolvimento local (Amaro, 1992: 152), as acções de formação e criação de emprego associadas a estes projectos têm contribuído para melhorar a formação de base das pessoas e "motivado o espírito de iniciativa e de crítica, o que é tanto mais digno de registo porque se trata de comunidades tradicionalmente deficitárias a esse respeito". Existe, pois, uma semente de iniciativa que novas políticas de desenvolvimento poderão ajudar a germinar em formas de desenvolvimento local como, por exemplo, as "explorações rurais". O referido estudo sugere vários pontos de 182 reflexão, a propósito da ligação das políticas de emprego e formação profissional 
a outras dimensões do desenvolvimento (Amaro, 1992: 156 ss.), das quais destacaríamos duas:

- "criação de estruturas formais de apoio técnico (jurídico, económico, contabilístico, financeiro, comercial, administrativo, etc)";

- "sociedades de capital de risco para o Desenvolvimento Local".

\section{CONCLUSÕES}

Este artigo baseia-se em investigação realizada em três aldeias da Serra do Montemuro, um espaço oficialmente considerado "área rural profunda", fortemente marcado pelo despovoamento e por um desequilíbrio demográfico. Uma das principais conclusões dessa investigação reside no facto de que iniciativas de desenvolvimento, feitas com pessoas particularmente desfavorecidas pela desigualdade de oportunidades de emprego - mulheres rurais - , podem ser uma base importante num processo de inversão das tendências de despovoamento e envelhecimento. Mais do que isso, estes casos do Montemuro constituem, para as comunidades locais onde se inserem, exemplos que fazem crescer a crença nas potencialidades locais de desenvolvimento.

Efectivamente, os pontos fortes das micro-empresas aqui tratadas residem no aproveitamento das vantagens do local. Os materiais e as tecnologias de produção locais tradicionais, as solidariedades e rivalidades locais constituem, no fundo, uma forte ligação telúrica interiorizada pelos actores locais que se pode manifestar na grande satisfação por conseguir o sucesso na própria terra.

A constituição destas empresas revela a capacidade de adaptação das pessoas em meio local, nomeadamente as mulheres, às oportunidades de conseguir maiores rendimentos. $O$ sonho de conseguir melhores condições de vida na aldeia pode vir a tornar-se realidade, graças à singularidade do próprio meio local, proporcionada pela tradição.

O relativo sucesso fez aumentar as aspirações. Pensamos que os rendimentos poderão ser aumentados, quando houver uma organização que permita a estas e a tantas outras micro-empresas espalhadas pelo país aproveitarem as suas vantagens, para concorrerem num contexto capitalista ${ }^{14}$.

Se o clima social local, no princípio hostil, expectável enquanto reacção à mudança, se vai tornando mais favorável com o reconhecimento social da obra feita, será legítimo esperar uma evolução no mesmo sentido por parte da sociedade global, muito particularmente dos organismos do Estado. Entre a escrita da primeira versão deste texto e a sua revisão final, vimos acentuar-se em Portugal a discussão sobre desenvolvimento local, artes e ofícios tradicionais, micro-empresas, pluriactividade. Destacamos duas realizações do Programa das Artes e Ofí- 
cios Tradicionais (PAOT) ${ }^{15}$ : o Seminário "As Artes e Ofícios Tradicionais e as Micro-Empresas Face ao Desenvolvimento Regional e Local", realizado em Julho de 1994, e um livro sobre os efeitos no desenvolvimento local das iniciativas de cinco grupos de artesãs ${ }^{16}$, incluindo os três por nós observados. Serão, porventura, sintomas de mudança nas atitudes face ao estatuto e ao papel das microempresas que, como as que foram objecto da nossa observação, numa lógica de pluriactividade aproveitam recursos tradicionais locais em meio rural?

\section{NOTAS}

1. INE, XIII Recenseamento da População.

2. INE, XII e XIII Recenseamentos da População e Estatísticas Demográficas 1980-1990.

3. INE, XII e XIII Recenseamentos da População.

4. Cf. também DIAS, 1992.

5. Na realidade, uma das empresas observadas não é cooperativa, mas não notámos diferenças significativas na sua lógica de funcionamento, relativamente às que juridicamente o são.

6. A formação de pequenas cooperativas é frequentemente apoiada pelos programas de formação profissional, aproveitados pelas agências de desenvolvimento para as áreas rurais.

7. Designadamente a CIDM, no caso por nós estudado.

8. Não sabemos o impacto deste problema nas vendas; talvez até seja positivo, porque a aventura de procurar o ponto de venda "remoto" poderá aumentar a autenticidade do produto artesanal e a satisfação do cliente!

9. Compreender o que gera satisfação nos potenciais clientes destes produtos é um passo essencial para melhorar a diferenciação, face à concorrência industrial e para que, com maiores margens de comercialização, se obterem melhores remunerações para as artesãs.

10. Em ocasião posterior à escrita da primeira versão deste texto, foi publicada no Expresso a série "Artefactos", com o apoio do IEFP, um exemplo do que pode ser feito para promover estes produtos e que não está ao alcance das empresas, consideradas isoladamente.

11. Esta tendência foi por nós observada em associações de comercialização de artesanato fora da área geográfica tratada neste texto.

12. Sobre a fraca sustentação do desenvolvimento assente na desqualificação profissional e desaproveitamento do saber-fazer tradicional, veja-se RODRIGUES, M. J. e NEVES, A. O. (Coords.) 1994, Políticas de Reestruturação, Emprego e Desenvolvimento Regional, Lisboa, IEFP.

13. Cf. "contextos de continuidade" versus "contextos de contraste" (ALMEIDA et al. 1992: 111 ss.).

14. Note-se que não deverão concorrer segundo uma lógica capitalista, porque tornar-se-iam industriais.

15. O PAOT foi criado pela Resolução do Conselho de Ministros n. $.^{\circ} 47 / 92$, publicada no Diário da República, I Série-B, N. ${ }^{\circ} 295$. Embora o seu âmbito não se restrinja ao meio rural, tem sido evidente uma orientação para as potencialidades das "artes e ofícios tradicinais" nas áreas rurais, permitindo a sua inserção no contexto económico pluriactivo das explorações rurais.

16. CAVACO, Carminda e CALDEIRA, Maria José, 1994, Renovação das Artes Tradicionais na Serra de Montemuro, Lisboa, PAOT. 


\section{REFERÊNCIAS BIBLIOGRÁFICAS}

ALMEIDA, J.F. et al., 1992, Exclusão Social - Factores e Tipos de Pobreza em Portugal, Oeiras, Celta Editora.

AMARO, Rogério Roque (coord.), 1992, Iniciativas de Desenvolvimento Local - Caracterização de Alguns Exemplos, Lisboa, ISCTE/IEFP.

CABRAL, M. Villaverde, 1981, "A ética dos estudos camponeses: notas breves para uma reflexão sobre o campesinato e o seu 'futuro' em Portugal”, Revista Crítica de Ciências Sociais, 7/8, 135-148.

CABRAL, M. Villaverde, 1983, "A economia subterrânea vem ao de cima: estratégias da população rural perante a industrialização e a urbanização”, Análise Social, 76, 199-234.

CAVACO, Carminda, 1991, "Considerações em torno do desenvolvimento rural numa perspectiva espaço-temporal", Comunicação às Jornadas de Desenvolvimento Rural do Norte, Ponte de Lima.

DIAS, Maria Olívia, 1992, "Influência da transformação do 'status' e do papel da mulher sobre a natalidade", Gestão e Desenvolvimento, 1, 59-86.

GOMES, Bertina Sousa, 1986, "As mulheres em processo de socialização. Algumas questões acerca das sua representações”, Análise Social, 92/93, 813-824.

GROS, Marielle, 1993, "Luta contra a exclusão social: assistencialismo ou desenvolvimento local" in Estruturas Sociais e Desenvolvimento - Actas do II Congresso Português de Sociologia, Lisboa, Fragmentos.

JACINTO, R. et al., 1993, "Das dinâmicas territoriais aos processos de desenvolvimento das áreas rurais da Região Centro", Jornadas de Reflexão Sobre o PDR e o Mundo Rural, Lisboa.

KONING, Marijke de, 1986, "Da palavra à acção: história de um processo de conscientização de mulheres", Análise Social, 92/93, 825-852.

MARQUES, Carlos, PORTELA José e CRISTÓVÃO, Artur, 1993, Avaliação Qualitativa da Rede de Comercialização de Artesanato, Vila Real, UTAD.

PORTELA, José, 1994, "Micro-Empresas Rurais e Macro-Visões Urbanas: da hostilidade à amenidade do clima envolvente?", Comunicação ao Seminário As Artes e Oficios Tradicionais e as Micro-Empresas Face ao Desenvolvimento Regional e Local, Lisboa.

WALL, Karin, 1986, “A divisão sexual do trabalho na agricultura: elementos para o seu estudo”, Análise Social, 92/93, 661-668. 